known to be slow and erratic. Today, it would seem best to use a water-soluble compound, such as hydrocortisone hemisuccinate or prednisolone phosphate, by a parenteral route whenever it is not feasible to give corticosteroids by mouth to provide a 'cortisone cover'.

However, these minor and personal criticisms should not be taken as detracting in a significant way from the book's many virtues. The authors can be congratulated on writing in such a compact form a book which deserves to be read by general practitioners and all who deal with emergencies in hospital. It can be specially recommended to the newly-qualified doctor who finds himself in a post involving the handling of medical or surgical emergencies.

\section{Non-Infective Disease in Africa}

H. C. Trowell, O.B.E., M.D., F.R.C.P. Pp. vii +48 I, illustrated. London: Edward Arnold. 1960. $£ 3$ ros.

This unique and informative book, the quintessence of 29 years' clinical experience in Africa, is not only a valuable reference book for doctors working in Africa south of the Sahara but contains much of interest to doctors the world over. The reason for this is that Dr. Trowell has not strictly confined himself to describing the pattern of non-infective disease in Africans; comparisons are made with the pattern of disease in people of African stock living outside Africa (e.g. American negroes) and in Europeans. In addition, a full and up-to-date bibliography is supplied.

In these pages Dr. Trowell describes diseases of liver, heart and circulation, blood, metabolism, nutrition, nervous and endocrine systems, and of urinary and alimentary tracts, and many questions are posed. Why should coronary atherosclerosis be so rare in Africans and hypertension so common? Why should endomyocardial fibrosis occur almost exclusively in Africans? Why is the milieu interieur of the African so significantly different from that of the European? These and many other questions are discussed in the text, and the attention of research workers is drawn to a number of problems requiring elucidation.

It is a pity that so many printing errors were allowed to pass the proof-reading stage, but these will doubtless be corrected when the second impression of this excellent book appears.

\section{Valvular Disease of the Heart in Old Age}

P. D. BEDFord and F. I. CAIRD. Pp. $x+$ r94, with 32 illustrations. London: J. \& A. Churchill. 1960. 30s.

This is an excellent monograph which should be read by all general physicians as well as by cardiologists and geriatricians, for the authors have presented with great clarity a large amount of interesting information not otherwise easy to come by, and raise a number of stimulating problems for thought, as Dr. Paul Wood indicates in his foreword.

The material is drawn from the authors' geriatric unit at the Cowley Road Hospital, Oxford, to which 3,124 patients, aged $6_{5}$ and over, were admitted in the $6 \frac{1}{2}$ years up to January 1956 . Approximately 2 i \% were admitted chiefly because of disease of the heart and great vessels, and valvular disease was diagnosed in $13.4 \%$ of all admissions. This material is fully analysed and discussed, and many interesting observations are made. Prognosis and treatment, as well as diagnosis, are dealt with: the stress laid on anticoagulant therapy in heart failure in the elderly is noteworthy. There are some excellent photographs of valvular deformities in autopsy specimens.

\section{Recent Advances in Renal Disease}

Edited by M. D. MiLne. The proceedings of a conference held in London at the Royal College of Physicians of London, July 22 to $23,1960$. Pp. ix +254 , illustrated. London: Pitman Medical Publishing Co. 196r. 25 s.

This was the fourth of the Scientific Conferences now being held regularly at the Royal College of Physicians, at which distinguished speakers review recent advances in their particular field. The Proceedings of each one are being published in a few months in a clear type and limp cover at a reasonable price, with a verbatim report of the discussions held after the papers. The six sessions at this conference were devoted to Renal Function and Structure, Acute Renal Failure, the Nephrotic Syndrome, Pyelonephritis, Metabolic Aspects of Renal Disease, and Hypertension and the Kidney, the chairmen being Professor McCance, Lord Evans, Sir Robert Platt, and Professor J. McMichael. Anyone who wants a really up-to-date review of recent work in this field is recommended to buy this book. There is a good selection of references and an index, as well as a large number of figures. The publishers are to be congratulated on producing these Proceedings so accurately, quickly and cheaply.

\section{Cerebral Palsy in Childhood and Adolescence}

A Medical, Psychological and Social Study. Edited by J. L. HENDERSON, M.D., F.R.C.P.E. Pp. viii + 403. Edinburgh and London: E. \& S. Livingstone. 1961. 35 s.

This is an account of a field survey of cerebral palsy made in Scotland. It is characterized by its careful design, broad scope and thorough execution. In the clinical sphere, a pediatrician, an orthopædist, an ophthalmologist, an ear, nose and throat specialist, and a dental surgeon were all concerned, and in addition extensive psychological and social studies were done. The incidence of the condition was about two per thousand. There were 301 cases proposed for inclusion in the survey, but no less than 6r children, hitherto diagnosed as suffering from cerebral palsy, were found not to have this condition. The book is packed with valuable data and it is difficult to single out the more important points in a review. A striking feature was the considerable proportion of children for whom the full range of medical services had not been mobilized. For example, a quarter had not previously seen an orthopædic surgeon and deafness had not previously been suspected in two-thirds of those who were in fact deaf. The dental condition of the children was likewise much below that prevailing among children in the area of the survey. Psychological assessment showed that almost $50 \%$ had an I.Q. below 70 , an important fact in view of the implication sometimes made that the only disability of the cerebral palsy child is in the physical sphere. These are but a few points from what is an admirable and model survey, and those who come into contact with cerebral palsy will wish to have this book by them not only to read but also for constant reference.

\section{Assessment of the Activity of Disease}

J. S. Lawrence, M.D., M.R.C.P. Pp. viii +252 , with 34 tables and 37 illustrations. London: H. K. Lewis. 1961. 42s.

This is a complete treatise on the erythrocyte sedimentation rate, the first half presenting the full biochemical background of plasma viscosity and plasma protein variation, and, after a description of methods, the 